\title{
Study on effect of social media on youth
}

\section{Sonia Langthasa}

Received: 16.07.2019; Revised: 09.11.2019; Accepted: 23.11.2019

Authors for Correspondence

\section{Sonia Langthasa}

Department of Family Resource Management and Consumer Science, College of Community Science, Assam Agricultural

University, Jorhat (Assam) India Email : sonialangthasa867@ gmail.com
ABSTRACT : Technological advancement has led to use us many tools, devices and sites to connect different people from each and every corner of the world. Usage of information technology in social media, increase its popularity in the youth. The objective of this study is an attempt to investigate the extent of effect of social media on the youth. The reason for selecting youth as the target audience is because the direction of a country and culture is decided by the direction taken by youths of that country. For analyzing the effects of social media on youths, the questionnaire study was designed and by following simple random samping from two villages i.e., Dillaji Mithiphang and Beltola of Diphu, 200 samples were selected. The results shows that social media was used for communication and entertainment purpose.

KEY WORDS: Communication, Entertainment, Social media, Technological

- HOW TO CITE THIS PAPER : Langthasa, Sonia (2019). Study on effect of social media on youth. Asian J. Home Sci., 14 (2) : 432-435, DOI: 10.15740/HAS/AJHS/14.2/432-435. Copyright@ 2019: Hind AgriHorticultural Society. 